\title{
Contaminant Removal by Wastewater Treatment Plants in the Stillaguamish River Basin, Washington
}

\section{Introduction}

Human activities in most areas of the developed world typically release nutrients, pharmaceuticals, personal care products, pesticides, and other contaminants into the environment, many of which reach freshwater ecosystems. In urbanized areas, wastewater treatment plants (WWTPs) are critical facilities for collecting and reducing the amounts of wastewater contaminants (WWCs) that ultimately discharge to rivers, coastal areas, and groundwater. Most WWTPs use multiple methods to remove contaminants from wastewater. These include physical methods to remove solid materials (primary treatment), biological and chemical methods to remove most organic matter (secondary treatment), advanced methods to reduce the concentrations of various contaminants such as nitrogen, phosphorus and (or) synthetic organic compounds (tertiary treatment), and disinfection prior to discharge (Metcalf and Eddy, Inc., 1979). This study examined the extent to which 114 organic WWCs were removed by each of three WWTPs, prior to discharge to freshwater and marine ecosystems, in a rapidly developing area in northwestern Washington State. Removal percentages for each WWC were estimated by comparing the concentrations measured in the WWTP influents with those measured in the effluents. The investigation was carried out in the 700-mi² Stillaguamish River Basin, the fifth largest watershed that discharges to Puget Sound (fig. 1).

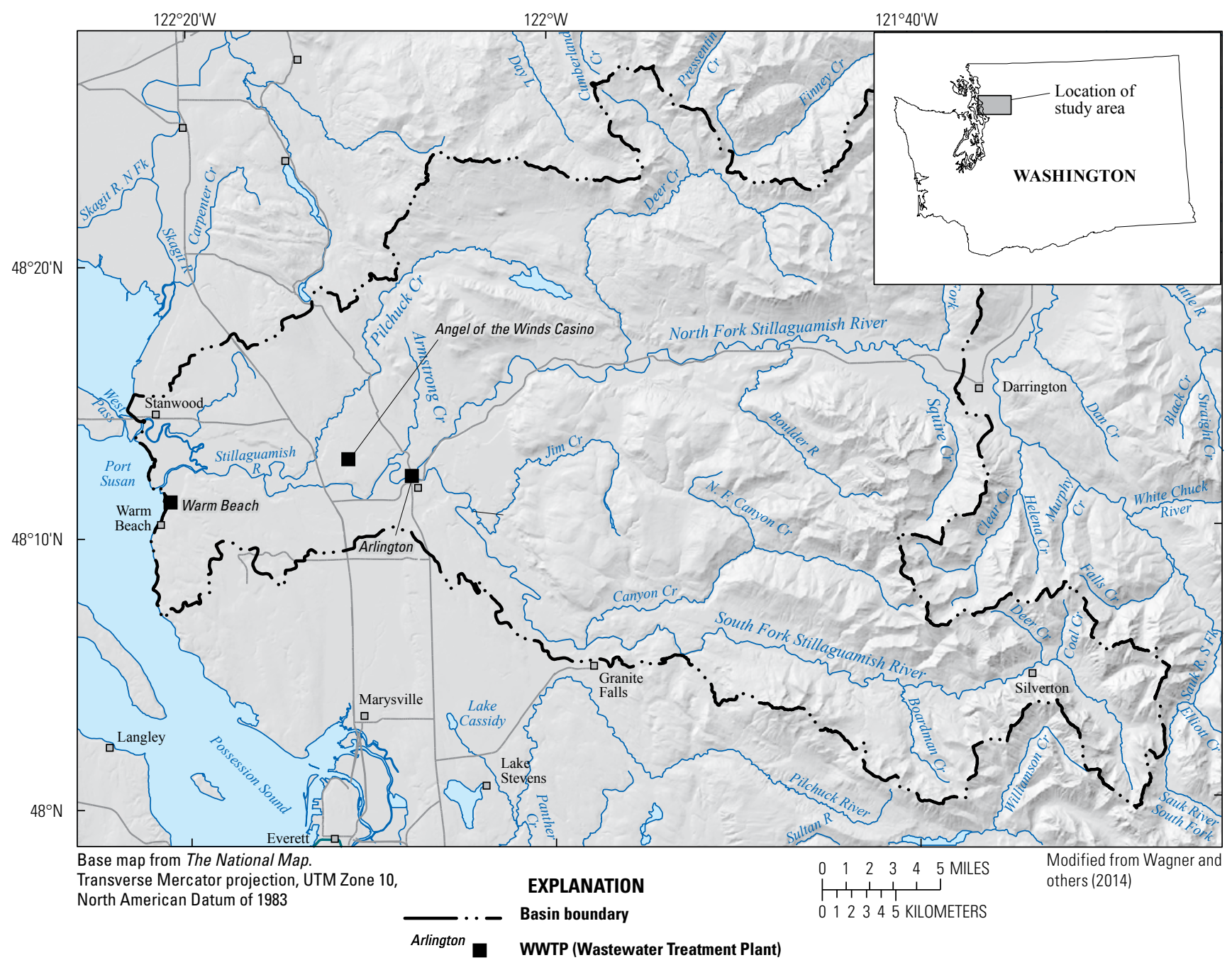

Figure 1. Locations of the wastewater treatment plants sampled in the Stillaguamish River Basin, 2009-11. (Modified from Wagner and others, 2014.) 
Table 1. Characteristics of the wastewater treatment plants sampled in the Stillaguamish River Basin, 2009-11.

[Wastewater treatment plant: Years of sample collection are in parentheses. mm, millimeter]

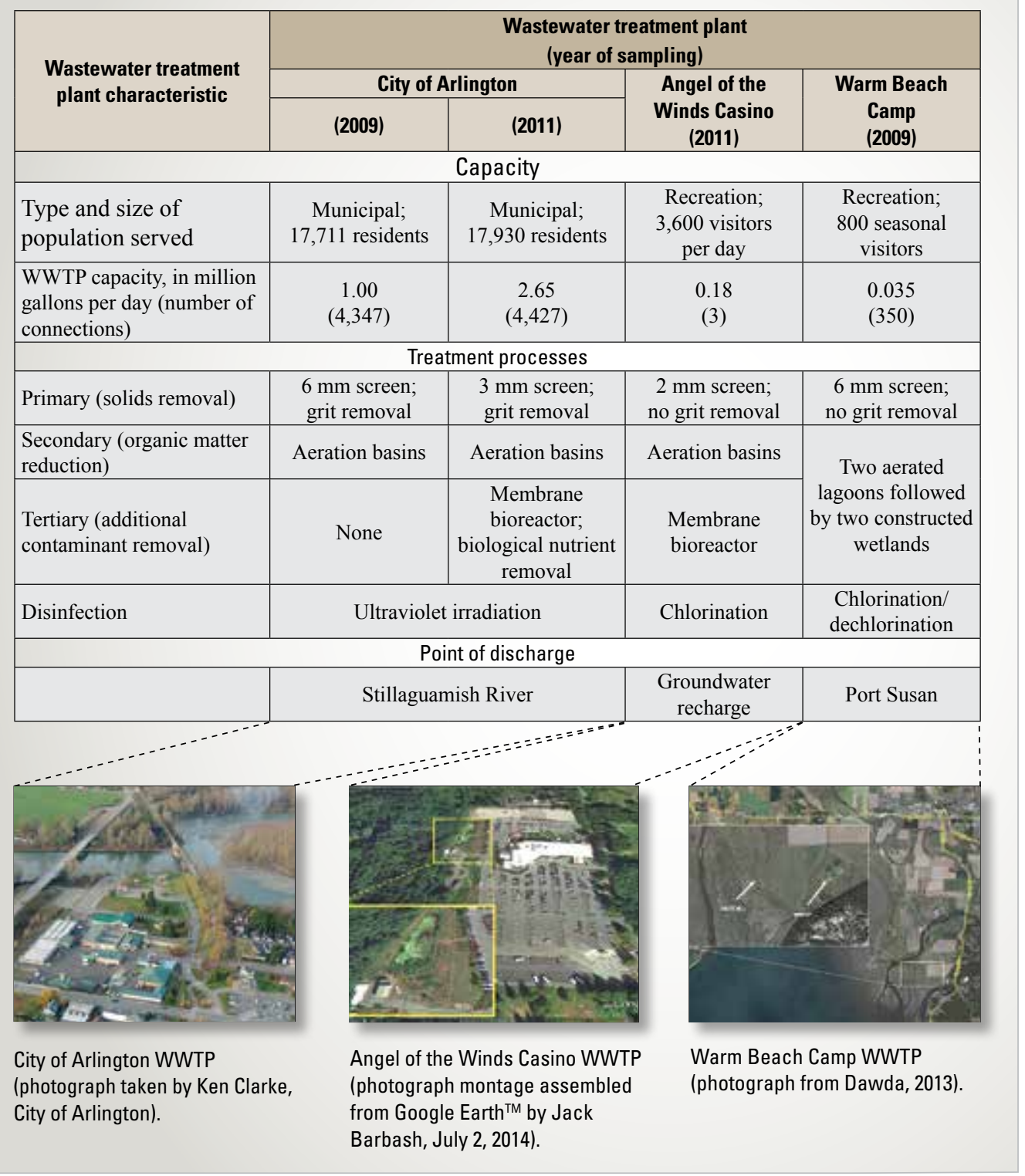

\section{Study Sites and Methods}

The locations of the three WWTPs are shown in figure 1 . The major watertreatment processes used by the three facilities are summarized in table 1 . As indicated in table 1, prior to the 2011 sampling, the City of Arlington WWTP underwent a major upgrade that included the addition of a membrane bioreactor (MBR) and biological nutrient removal (BNR) to enhance contaminant removal. At each of the three WWTPs, paired samples of the influent and effluent were collected every 6 hours and composited over the same 24-hour period by the WWTP operators or by the Stillaguamish
Tribe of Indians. The composited influent and effluent samples were filtered and processed by the U.S. Geological Survey (USGS), and analyzed for their chemical composition at the USGS National Water-Quality Laboratory. The procedures used to characterize the physical and chemical conditions of the sampled waters, and to collect, preserve, and chemically analyze the samples, are described by Wagner and others (2014).

Removal percentages for each WWC were computed using the approach described by the U.S. Environmental Protection Agency (2010). For WWCs that were detected in the influent of a WWTP but not in the effluent, the removal percentages reported here represent minimum estimates. When this occurred for the two
WWCs that were detected in field blanks at concentrations exceeding their reporting limits (benzophenone and camphor), the minimum removal percentages were computed using the maximum field blank concentration, rather than the reporting limit. The maximum non-significant difference (MNSD) between removal percentages for a given WWC $(\alpha=$ 0.05 ) was computed using the results reported from the analysis of spiked replicates of surface-water samples for the analytical method used for the compound of interest (Furlong and others, 2008; Zaugg and others, 2006, 2014).

\section{Contaminant Removal by the Wastewater Treatment Plants}

Removal percentages are shown in figure 2 for the 16 WWCs for which removal percentages could be computed for all three WWTPs. The study results for the remaining 98 compounds are summarized in table 2, which shows the removal percentages for individual contaminants at the individual facilities. Table 2 also identifies instances where (1) the WWC was not detected in the influent; (2) the effluent concentration was greater than the influent concentration; (3) the chemical analyses were inconclusive because interfering substances were present, the compound was detected in the influent at its reporting limit, or the compound was not detected in the effluent using a reporting limit that was greater than the measured influent concentration; or (4) the analyses were incomplete because one of the samples (influent or effluent) was not analyzed, the maximum analyte recovery was less than 35 percent for one or more of the WWTPs, or at least one of the samples was not filtered prior to analysis.

Among the 114 WWCs examined for this study, 71 were detected in the influent of 1 or more of the 3 WWTPs. Of the 52 WWCs for which removal percentages could be computed at 1 or more of the WWTPs, nearly all the compounds 


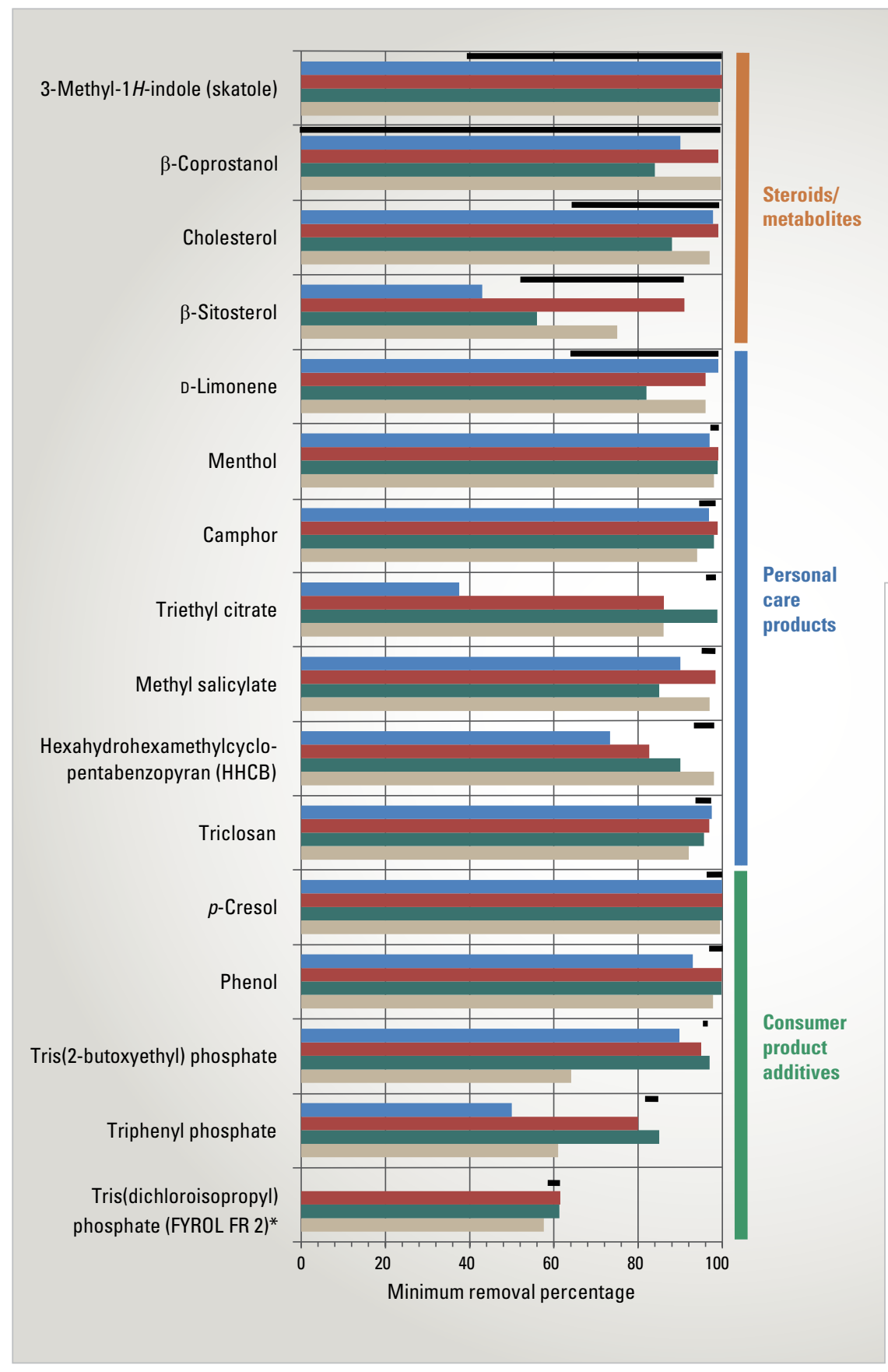

(51) exhibited removal percentages greater than zero, and most compounds (49) showed removal percentages greater than 50 percent at 1 or more of the facilities. (Confidence in the removal percentages at the WWTPs examined for this study, however, was constrained because the influent and effluent for each facility were sampled only once in each year of interest.) The data shown in figure 2 and table 2 also indicate that after the MBR and BNR were added to the City of Arlington WWTP, significantly higher removal percentages were observed for eight compounds, and none showed a significantly lower removal percentage. (It was not possible to identify increases or decreases in removal percentages for a given compound after the MBR and BNR were installed if the removal percentages before and after the MBR and BNR installation were both minimum values - as was the case for $\beta$-sitosterol—or if only one removal percentage was a minimum value, but less than the other, as was the case for benzophenone.) The results from this study indicate that the water treatment processes used by these three WWTPs reduce the concentrations of many WWCs in the wastewater from the communities served by these facilities prior to discharge into the hydrologic system.

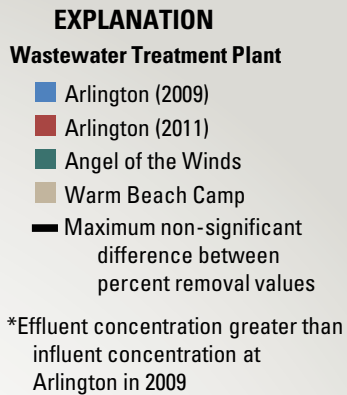

Figure 2. Minimum removal percentages for 16 wastewater contaminants at the 3 wastewater treatment plants, Stillaguamish River Basin, 2009-11.

\section{Acknowledgments}

The authors wish to express their appreciation to Jennifer Sevigny, Jody Pope (Stillaguamish Tribe of Indians), Erik Thornburgh (Operator of the Angel of the Winds Casino and Warm Beach Camp WWTPs), Fred Rapelyea (Arlington WWTP Supervisor), and Raegan Huffman (USGS Washington Water Science Center) for their valuable assistance on this project.

\section{References Cited}

Dawda, Mike, 2013, Fact sheet for NPDES permit WA0029904-Warm Beach Christian Camps and Conference Center: Bellevue, Wash., Washington Department of Ecology Fact Sheet, 53 p.

Furlong, E.T., Werner, S.L., Anderson, B.D., and Cahill, J.D., 2008, Determination of human-health pharmaceuticals in filtered water by chemically modified styrene-divinylbenzene resin-based solid-phase extraction and high-performance liquid chromatography/mass spectrometry: U.S. Geological Survey Techniques and Methods, book 5, chap B5, $56 \mathrm{p}$.

Metcalf and Eddy, Inc., 1979, Wastewater engineering - Treatment, disposal, reuse, 2nd ed., (revised by George Tchobanoglous): San Francisco, McGraw-Hill, 920 p.

U.S. Environmental Protection Agency, 2010, Treating contaminants of emerging concern-A literature review database: Washington, D.C., U.S. Environmental Protection Agency report EPA820-R-10-002, 27 p., plus 4 appendixes.

Wagner, R.J., Moran, P.W., Zaugg, S.D., Sevigny, J.M., and Pope, J.M., 2014, Contaminants of emerging concern in the lower Stillaguamish River Basin, Washington, 2008-11: U.S. Geological Survey Open-File Report 2014-1028, 8 p.

Zaugg, S.D., Phillips, P.J., and Smith, S.G., 2014, Analysis of pharmaceutical and other organic wastewater compounds in filtered and unfiltered water samples by gas chromatography/mass spectrometry: U.S. Geological Survey Open-File Report 2013-1297, 24 p. 
Table 2. Removal percentages for 92 wastewater contaminants for which removal percentages could not be computed for one or more of the wastewater treatment plants studied in the Stillaguamish River Basin, 2009-11.

[Shading-Tan, not detected in influent; green, effluent concentration greater than influent concentration. Not detected in influent or effluent of any WWTP: 5-Methyl-1 $H$-benzotriazole;

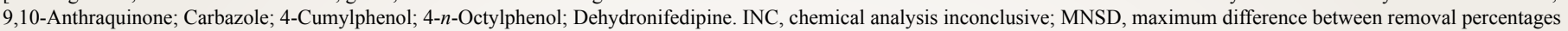

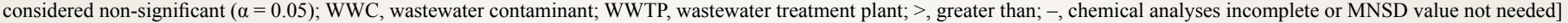

\begin{tabular}{|c|c|c|c|c|c|}
\hline \multirow{3}{*}{ WWC } & \multicolumn{5}{|c|}{ WWC removal percentage at WWTP } \\
\hline & \multicolumn{2}{|c|}{ City of Arlington } & \multirow{2}{*}{$\begin{array}{l}\text { Angel of the } \\
\text { Winds Casino } \\
\text { (2011) }\end{array}$} & \multirow{2}{*}{$\begin{array}{c}\text { Warm Beach } \\
\text { Camp } \\
\text { (2009) }\end{array}$} & \multirow{2}{*}{ MNSD } \\
\hline & (2009) & (2011) & & & \\
\hline
\end{tabular}

Consumer product additives

1,4-Dichlorobenzene

3-tert-Butyl-4-hydroxyanisole

Acetophenone

Acetyl hexamethyl tetrahydro naphthalene (AHTN)

Benzophenone

Isoborneol

Isophorone

Isopropylbenzene

Isoquinoline

$\mathrm{N}, \mathrm{N}$-diethyl- $\mathrm{m}$-toluamide (DEET)

Tetrachloroethene

Tributylphosphate

Tris(2-chloroethyl) phosphate (FYROL CEF)

Consumer product metabolites

1,7-Dimethylxanthine

2-Ethyl-2-phenylmalonamide

4-Nonylphenols (sum of all isomers)

4-Nonylphenol diethoxylates (sum of all isomers)

4-tert-Octylphenol diethoxylate

4-tert-Octylphenol monoethoxylate

4-tert-Octylphenol

Cotinine

Natural biochemicals

$\beta$-Stigmastanol

Indole

Pesticides

Bromacil

Carbaryl

Chlorpyrifos

Diazinon

Metalaxyl

Metolachlor

Piperonyl butoxide

Prometon

Petroleum-derived compounds

1-Methylnaphthalene

2,6-Dimethylnaphthalene

2-Methylnaphthalene

Anthracene

Benzo $[a]$ pyrene

Fluoranthene

Naphthalene

Phenanthrene

Pyrene

Pharmaceuticals

Acetaminophen

Albuterol
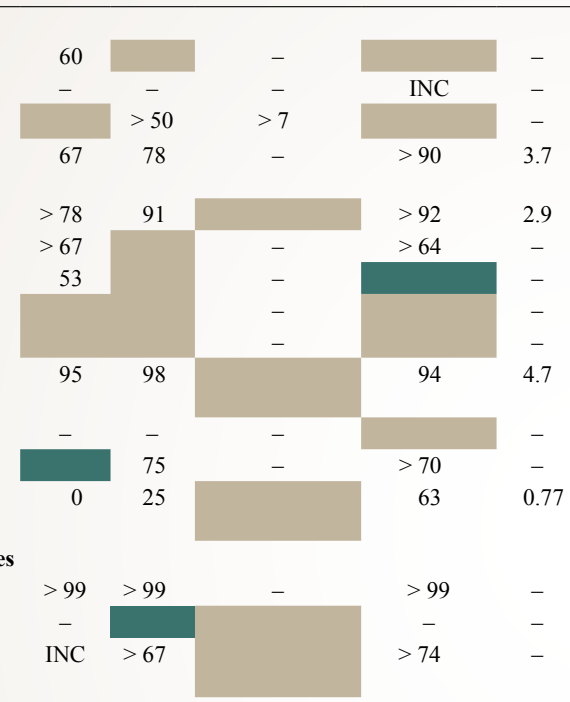

$75 \quad 93$

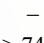

$>74$

90

INC $>67$

$>99$

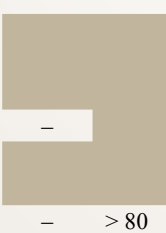

$>44$
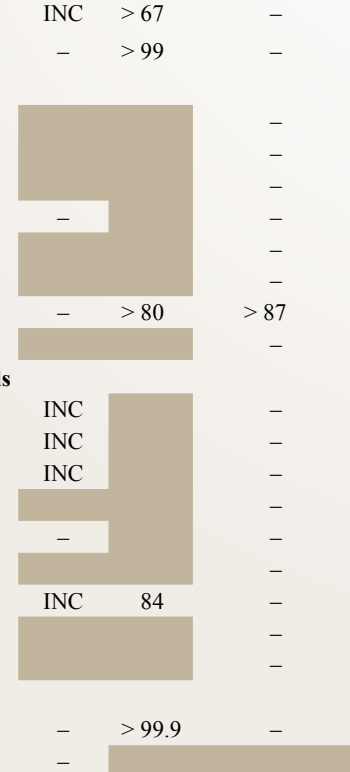

INC

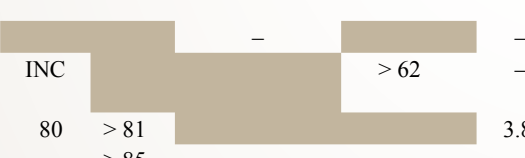

\begin{tabular}{|c|c|c|c|c|c|}
\hline \multirow{3}{*}{ WWC } & \multicolumn{5}{|c|}{ WWC removal percentage at WWTP } \\
\hline & \multicolumn{2}{|c|}{ City of Arlington } & \multirow{2}{*}{$\begin{array}{l}\text { Angel of the } \\
\text { Winds Casino } \\
\text { (2011) }\end{array}$} & \multirow{2}{*}{$\begin{array}{c}\text { Warm Beach } \\
\text { Camp } \\
\text { (2009) }\end{array}$} & \multirow{2}{*}{ MNSD } \\
\hline & (2009) & (2011) & & & \\
\hline
\end{tabular}

Pharmaceuticals-Continued

Amitriptyline

Antipyrine

Butalbital

Caffeine

Carbamazepine

Carisoprodol

Celecoxib

Chloroxylenol

Chlorpheniramine

Citalopram

Codeine

Dextromethorphan

Diazepam

Dihydrocodeine

Diltiazem

Diphenhydramine

Efavirenz

Fluconazole

Griseofulvin

Hydrocodone

Ibuprofen

Iminostilbene

Lidocaine

Meperidine

Meprobamate

Metaxalone

Methadone

Methocarbamol

Methylphenidate

Oxcarbazepine

Oxycodone

Pentobarbital

Pentoxifylline

Phendimetrazine

Phenobarbital

Phenytoin

Primidone

Propofol

Sulfamethoxazole

Temazepam

Thiabendazole

Ticlopidine

Tramadol

Trimethoprim

Venlafaxine

Verapamil

Warfarin

Pharmaceutical metabolites

Chirald

Norpropoxyphene

Trihalomethanes

Tribromomethane
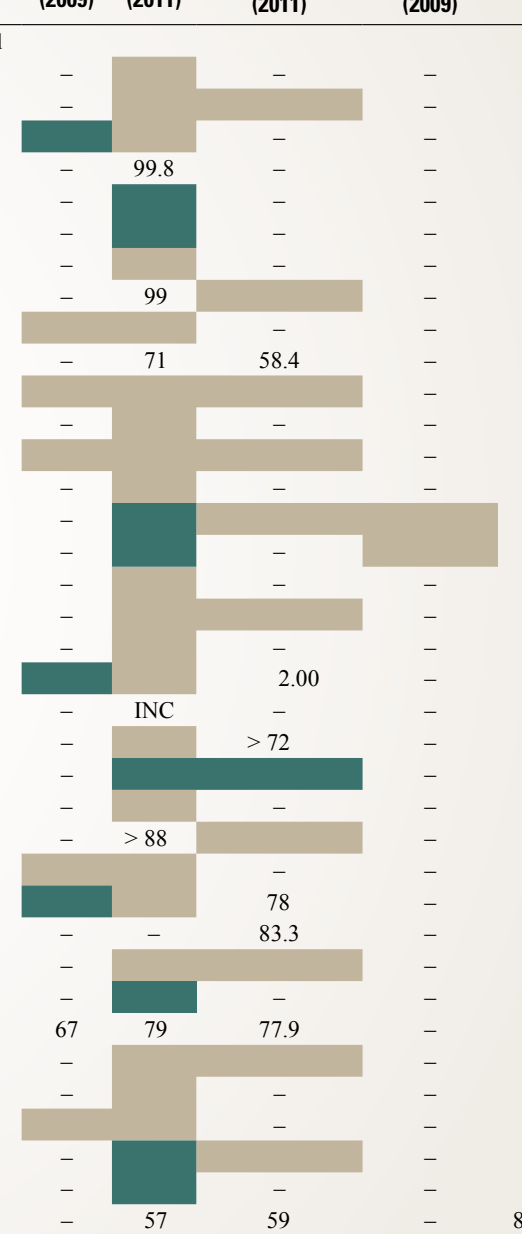

Zaugg, S.D., Smith, S.G., and Schroeder, M.P., 2006, Determination of wastewater compounds in whole water by continuous liquidliquid extraction and capillary-column gas chromatography/mass spectrometry: U.S. Geological Survey Techniques and Methods, book 5, chap. B4, $30 \mathrm{p}$.

Publishing support provided by the U.S. Geological Survey Tacoma Publishing Service Center
Authors: Jack E. Barbash, Patrick W. Moran, Richard J. Wagner (U.S. Geological Survey), and Mike Wolanek (City of Arlington Wastewater Treatment Plant)

\section{For Information Contact:}

U.S. Geological Survey

Director, Washington Water Science Center

934 Broadway, Suite 300

Tacoma, WA 98402
ISSN 2327-6932 (online) http://dx.doi.org/10.3133/fs20153023 